\title{
Microbial Diversity in Patients with Gastroduodenal Diseases
}

\author{
Shorena Khetsuriani, Klara Khetsuriani \\ Scientific Skills Center, Tbilisi State Medical University, Georgia \\ Email: shorenamd@gmail.com
}

Received October 25, 2013; revised November 25, 2013; accepted December 1, 2014

Copyright (c) 2014 Shorena Khetsuriani, Klara Khetsuriani. This is an open access article distributed under the Creative Commons Attribution License, which permits unrestricted use, distribution, and reproduction in any medium, provided the original work is properly cited. In accordance of the Creative Commons Attribution License all Copyrights (C) 2014 are reserved for SCIRP and the owner of the intellectual property Shorena Khetsuriani, Klara Khetsuriani. All Copyright (c) 2014 are guarded by law and by SCIRP as a guardian.

\begin{abstract}
H. pylori infection is mainly spread in the kind of gastroduodenal diseases: chronic gastritis, peptic ulcer disease, MALT-lymphoma, gastric cancer. According to certain literature, the mentioned bacterium causes diseases of other visceral organs of humans. Study of the aggravating impact of this infection is under the attention of the scientists. However, other infectious agents, including fungi, other bacteria, parasites, and viruses and their role in different gastroduodenal diseases are not studied enough. The aim of our study was to identify mucous (parietal) gastroduodenal microflora in patients with different diseases of this zone. 390 patients with chronic gastritis (CG), peptic ulcer diseases (PUD) and gastric cancer (GC) were included in the study. The resection materials and biopsy specimens were taken during the operation or endoscopy procedures. Identification of strains $\boldsymbol{H}$. pylori, Candida spp and others was performed by established methods, on the basis of morphological, tinctorial, cultural and biochemical properties. Microflora of patients with different gastroduodenal diseases is diverse enough. It is represented by facultative, obligate anaerobes, microaeropilic bacteria. More frequently, there were $H$. pylori and Candida sp, as well as in associations and monocultures. The obtained results confirmed the wide distribution of $\boldsymbol{H}$. pylori and Candida spp and their frequent coexistence in patients with gastric cancer, chronic gastritis and peptic ulcer disease. Microflora of patients with CG and GC was represented on 11 species. Microflora of patients with PUD-13 species was more diverse.
\end{abstract}

\section{KEYWORDS}

\section{Gastroduodenal Microflora; Gastric Cancer; Peptic Ulcer Disease; Chronic Gastritis; H. pylori; Candida spp}

\section{Introduction}

The gastrointestinal tract from oral cavity to distal colon represents a variety of habitats with the stomach being the most extreme one [1]. Older studies attempted to cultivate organisms from the gastric juices or mucosal biopsies. It was generally assumed that very few bacteria were able to survive in the strongly acidic environment of the stomach [2,3]. Studies demonstrate that relatively few bacteria are resident in the stomach and those that are found are through to be simply passing through. However, studies have used a metagenomic approach to investigating the gastric mucosa in individuals [4,5]. Results of these studies illustrate that the stomach has abundant and diverse microfloras with high inter-subject variation. The main phylotypes are identified belonging to the Firmicutes, Actinobacteria, Fusobacteria, Bacteroides, Proteobacteria with the major component being the Firmicutes [6]. More recently culture independent studies of the stomach have been conducted to detect and quantify specific pathogens, such as $H$. pylori [1]. $H$. pylori infection represents a key factor in the etiology of various gastrointestinal diseases, ranging from chronic active gastritis without clinical symptoms to peptic ulceration, gastric adenocarcinoma, and gastric mucosa-associated lymphoid tissue lymphoma $[2,7,8]$. Gastric pathology can be caused by other infectious agents, including fungi, other bacteria, parasites, and viruses. These infectious agents are frequently part of a systemic process in which the re- 
sulting gastric pathology is one of the manifestations. Other microorganisms cause primary gastric pathology. Analysis of relationship between selected disorders of upper gastrointestinal tract and infection with $H$. pylori and/or Candida spp revealed a link between coexistence of $H$. pylori with Candida and gastric ulcers suggesting synergism of those microorganism in pathogenesis of the disease [9]. The role of gastroduodenal mucous microflora in ulcer and gastritis course is studied. New approaches to effective treatment of gastroduodenal diseases may be developed with consideration of dysbacteriosis [10]. Study of the aggravating impact of this infection is under the attention of the scientists.

Considering the above said, the aim of our study was to identify mucous (parietal) gastroduodenal microflora in patients with different diseases of this zone.

\section{Materials and Methods}

390 patients with chronic gastritis (CG), peptic ulcer diseases (PUD) and gastric cancer (GC) were included in the study. The resection materials and biopsy specimens were obtained during the operation or endoscopy procedures. Identification of strains $H$. pylori, Candida spp and other were performed by established methods, on the basis of morphological, tinctorial, cultural and biochemical properties $[11,12]$.

\section{Results}

Frequency of microorganisms listed in Table 1, which shows that in greatest number were identified $H$. pylori$35.12 \% \pm 2.41 \%(C G-31.67 \% \pm 4.68 \%$; PUD-38.12\% $\pm 4.11 \%$; GC-36.66\% \pm 4.97\%) and Candida spp$15.89 \% \pm 1.84 \%(C G-16.14 \% \pm 2.88 \%$, PUD-15.10\% $\pm 3.02 \%$, CG $-16.66 \% \pm 3.92 \%)$. Other microbes have been much less common.

The microflora of patients with CG and GC was represented by 11 species. There was a more diverse microflora in patients with PUD-13 species.

We compared microflora in $H$. pylori-positive and $H$. pylori-negative patients (Tables 2 and 3).

In $H$. pylori-positive patients referred microorganisms were in monocultures in $10.21 \% \pm 2.58 \%$ cases $(\mathrm{CG}-$ $9.80 \% \pm 4.16 \%$; PUD-7.54\% $\pm 3.61 \%$; GC-15.15\% \pm $6.21 \%)$.

Among the microbial associations in the majority of cases were $H$. pylori + Candida spp-11.67\% $\pm 2.78 \%$ (CG-17.64\% \pm 5.33\%; PUD-18.86\% \pm 5.36\%; GC$15.15 \% \pm 6.21 \%)$ and $H$. pylori + Clostridium spp$10.94 \% \pm 2.66 \%$. This association was frequent only in cases of PUD- $(9.43 \% \pm 4.0 \%)$ and GC $(24.24 \% \pm$ $7.42 \%)$ in comparison of CG $(3.92 \% \pm 5.93 \%)$. There were small amounts of $H$. pylori + Pseudomonas spp and H. pylori + Enterococcus spp (both $2.21 \% \pm 1.19 \%$ ) associations.

Among $H$. pylori-negative patients in monocultures were only Candida spp-21.05\% \pm 4.67\% (CG-22.22\% \pm 6.92\%, PUD-15.0\% \pm 7.98\%, GC-25.0\% \pm 9.68\%). Other microorganisms were in associations (Table 3). More frequent were Candida spp + Staphylococcus spp

Table 1. Frequency of microorganisms.

\begin{tabular}{|c|c|c|c|c|c|c|c|c|c|}
\hline \multirow{2}{*}{$\#$} & \multirow{2}{*}{ Microorganisms } & \multicolumn{2}{|c|}{$\mathrm{CG} n=161$} & \multicolumn{2}{|c|}{ PUD n = 139} & \multicolumn{2}{|c|}{$\mathrm{GC} n=90$} & \multicolumn{2}{|c|}{ Total $n=390$} \\
\hline & & abs & $\%$ & abs & $\%$ & abs & $\%$ & abs & $\%$ \\
\hline 1 & H.pylori & 51 & $31.6 \pm 4.68$ & 53 & $38.12 \pm 4.11$ & 33 & $36.66 \pm 4.97$ & 137 & $35.12 \pm 2.41$ \\
\hline 2 & Staphylococcus spp & 18 & $11.18 \pm 2.46$ & 12 & $8.63 \pm 2.37$ & 6 & $6.66 \pm 2.61$ & 36 & $9.23 \pm 1.46$ \\
\hline 3 & Streptococcus spp & 10 & $6.21 \pm 1.87$ & 11 & $7.91 \pm 2.28$ & 4 & $4.44 \pm 2.16$ & 25 & $6.41 \pm 1.23$ \\
\hline 4 & Escherichia spp & 6 & $3.72 \pm 1.48$ & 8 & $5.75 \pm 1.96$ & 6 & $6.66 \pm 2.61$ & 20 & $5.12 \pm 1.11$ \\
\hline 5 & Proteus spp & 10 & $6.21 \pm 1.87$ & 7 & $5.03 \pm 1.84$ & 4 & $4.44 \pm 2.16$ & 21 & $5.38 \pm 1.14$ \\
\hline 6 & Pseudomonas spp & 0 & - & 2 & $1.43 \pm 0.9$ & 1 & $1.11 \pm 1.09$ & 3 & $0.76 \pm 0.42$ \\
\hline 7 & Enterococcus spp & 0 & - & 2 & $1.43 \pm 0.9$ & 1 & $1.11 \pm 1.09$ & 3 & $0.76 \pm 0.42$ \\
\hline 8 & Bifidobacterium spp & 8 & $4.96 \pm 5.58$ & 3 & $2.15 \pm 1.18$ & 0 & - & 11 & $2.82 \pm 0.83$ \\
\hline 9 & Lactobacterium spp & 9 & $5.59 \pm 1.79$ & 5 & $5.03 \pm 1.84$ & 0 & - & 14 & $3.58 \pm 0.93$ \\
\hline 10 & Bacteroides spp & 10 & $6.21 \pm 1.87$ & 3 & $2.15 \pm 1.18$ & 6 & $6.66 \pm 2.61$ & 19 & $4.87 \pm 1.08$ \\
\hline 11 & Clostridium spp & 11 & $6.83 \pm 1.98$ & 11 & $7.91 \pm 2.28$ & 12 & $13.33 \pm 3.57$ & 34 & $8.71 \pm 1.42$ \\
\hline 12 & Pertostreptococcus spp & 2 & $1.24 \pm 0.85$ & 1 & $0.71 \pm 0.70$ & 2 & $2.22 \pm 1.54$ & 5 & $1.28 \pm 0.55$ \\
\hline 13 & Candida spp & 26 & $16.14 \pm 2.88$ & 21 & $15.10 \pm 3.02$ & 15 & $16.66 \pm 3.92$ & 62 & $15.89 \pm 1.84$ \\
\hline
\end{tabular}


Table 2. Microflora of $\boldsymbol{H}$. pylori-positive patients.

\begin{tabular}{|c|c|c|c|c|c|c|c|c|c|}
\hline \multirow{2}{*}{$\#$} & \multirow{2}{*}{ Microorganisms } & \multicolumn{2}{|c|}{$\mathrm{CG} n=51$} & \multicolumn{2}{|c|}{ PUD n = 53} & \multicolumn{2}{|c|}{ GC $n=33$} & \multicolumn{2}{|c|}{ Total n = 137} \\
\hline & & abs & $\%$ & abs & $\%$ & abs & $\%$ & abs & $\%$ \\
\hline 1 & H. pylori & 5 & $9.80 \pm 4.16$ & 4 & $7.54 \pm 3.61$ & 5 & $15.15 \pm 6.21$ & 14 & $10.21 \pm 2.58$ \\
\hline 2 & H. pylori + Candida spp & 9 & $17.64 \pm 5.33$ & 10 & $18.86 \pm 5.36$ & 5 & $15.15 \pm 6.21$ & 16 & $11.67 \pm 2.78$ \\
\hline 3 & H. pylori + Staphylococcus spp & 6 & $11.76 \pm 4.50$ & 6 & $11.32 \pm 4.34$ & 2 & $6.06 \pm 4.15$ & 14 & $10.21 \pm 2.58$ \\
\hline 4 & H. pylori + Streptococcus spp & 5 & $9.80 \pm 4.16$ & 7 & $13.20 \pm 4.64$ & 2 & $6.06 \pm 4.15$ & 14 & $10.21 \pm 2.58$ \\
\hline 5 & H. pylori + Escherichia spp & 4 & $7.84 \pm 3.75$ & 6 & $11.32 \pm 4.34$ & 4 & $12.12 \pm 1.63$ & 14 & $10.21 \pm 2.58$ \\
\hline 6 & H. pylori + Pseudomonas spp & 0 & - & 2 & $3.77 \pm 2.59$ & 1 & $3.03 \pm 2.98$ & 3 & $2.21 \pm 1.19$ \\
\hline 7 & H. pylori + Proteus spp & 4 & $7.84 \pm 3.75$ & 4 & $7.54 \pm 3.61$ & 1 & $3.03 \pm 2.98$ & 9 & $6.56 \pm 2.11$ \\
\hline 8 & H. pylori + Enterococcus spp & 0 & - & 2 & $3.77 \pm 2.59$ & 1 & $3.03 \pm 2.98$ & 3 & $2.21 \pm 1.49$ \\
\hline 9 & H. pylori + Bifidobacterium spp & 4 & $7.84 \pm 3.75$ & 2 & $3.77 \pm 2.59$ & 0 & - & 6 & $4.37 \pm 1.74$ \\
\hline 10 & H. pylori + bacteroides spp & 6 & $11.76 \pm 4.50$ & 3 & $5.66 \pm 3.15$ & 2 & $6.06 \pm 4.15$ & 11 & $8.02 \pm 2.30$ \\
\hline 11 & H. pylori + Peptostreptococcus spp & 2 & $3.92 \pm 5.93$ & 1 & $1.88 \pm 1.82$ & 2 & $6.06 \pm 4.15$ & 5 & $3.64 \pm 1.60$ \\
\hline 12 & H. pylori + Lactobacillus spp & 4 & $7.84 \pm 3.75$ & 1 & $1.88 \pm 1.82$ & 0 & - & 5 & $3.64 \pm 1.60$ \\
\hline 13 & H. pylori + Clostridium spp & 2 & $3.92 \pm 5.93$ & 5 & $9.43 \pm 4.0$ & 8 & $24.24 \pm 7.42$ & 15 & $10.94 \pm 2.66$ \\
\hline
\end{tabular}

Table 3. Microflora in $\boldsymbol{H}$. pylori-negative patients.

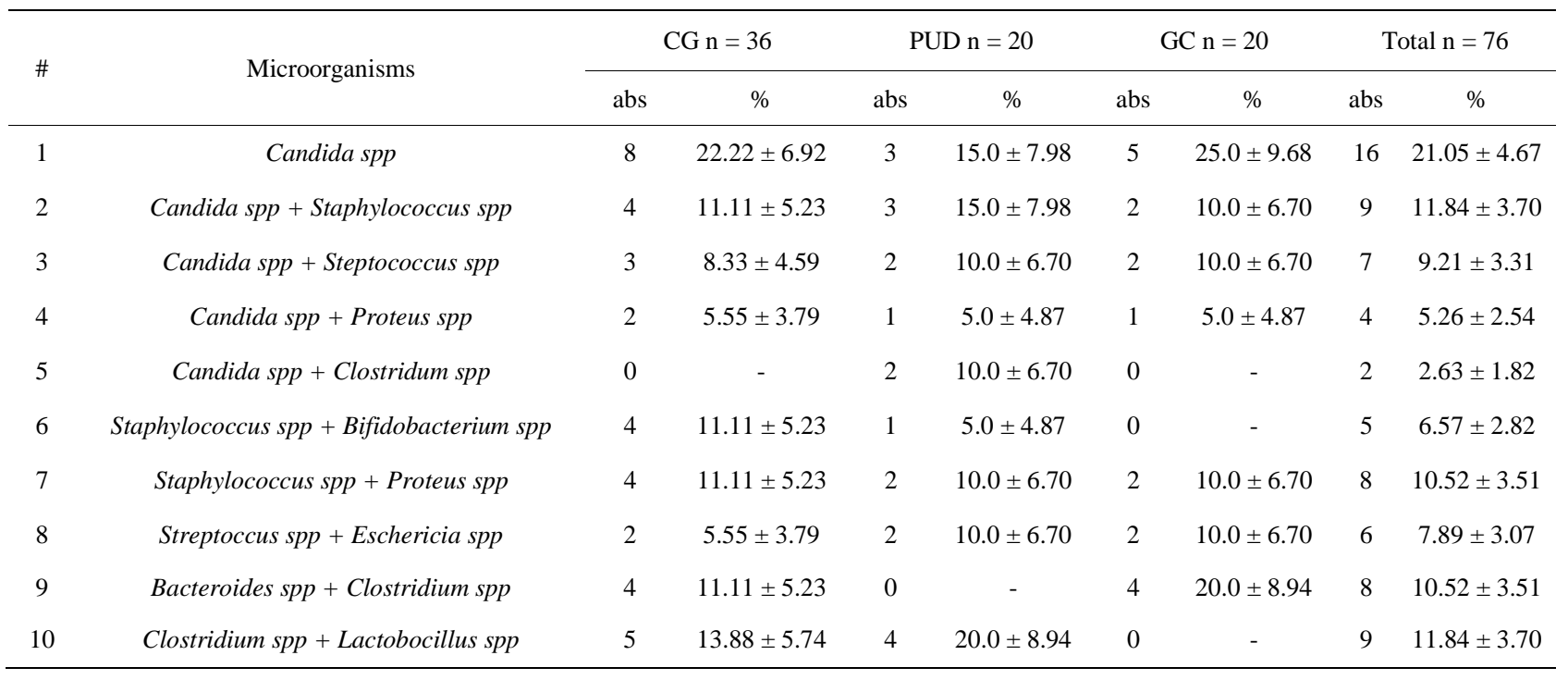

$-11.84 \% \pm 3.70 \%(C G-11.11 \% \pm 5.23 \%$, PUD-15.0\% $\pm 7.98 \%$; GC-10.0\% \pm 6.70\%) and Staphylococcus spp + Proteus spp and Bacteroides spp + Clostridium spp (both cases are equal-10.52\% $\pm 3.51 \%$ ).

\section{Conclusion}

The obtained results show that microflora of patients with different gastroduodenal diseases is diverse enough. It is represented by facultative, obligate anaerobes, microaeropilic bacteria. There were more frequent $H$. pylori and Candida spp, as well as in associations and monocultures. These results confirm the wide spread of $H$. pylori and Candida spp and their frequent coexistence in patients with gastric cancer, chronic gastritis and peptic ulcer disease. The microflora of patients with CG and GC was represented by 11 species. Microflora in patients with PUD-13 species was more diverse.

\section{REFERENCES}

[1] G. B. Huffnagle and M. G. I. Noverr, "Microbiota and Re- 
gulation of the Immune System,” 2008, pp. 16-24.

[2] K. E. L. McColl, "Helicobacter pylori Infection,” NEJM, Vol. 362, No. 17, 2010, pp. 1597-1604. http://dx.doi.org/10.1056/NEJMcp1001110

[3] D. C. Savage, "Microbial Ecology of the Gastrointestinal Tract," Annual Review of Microbiology, Vol. 31, 1977, pp. 107-139.

http://dx.doi.org/10.1146/annurev.mi.31.100177.000543

[4] A. F. Andersson, M. Undlerg, H. Jakobsson, et al., "Comparative Analysis of Human Gut Microflora by Barcode Pyrosequencing," PLoS ONE, Vol. 3, 2008, Article ID: e 2836.

[5] E. M. Bik, P. B. ECkburg, et al., "Molecular Analysis of the Bacterial Microbiota in the Human Stomach," Proceedings of the National Academy of Sciences, Vol. 102, 2006, pp. 732-737.

http://dx.doi.org/10.1073/pnas.0506655103

[6] J. Holton, "Peptic Ulcer Disease 2009, from “Genomic and Personalizes Medicine,” Vol. 1-2, 2nd Edition, pp. 914-935.

[7] J. G. Kusters, A. H. van Vliet and E. J. Kuipers, "Pathogenesis of Helicobacter pylori Infection,” Clinical Microbiology Reviews, Vol. 19, No. 3, 2006, pp. 449-490.
http://dx.doi.org/10.1128/CMR.00054-05

[8] I. M. Toller, et al., "Carcinogenic Bacterial Pathogen $\mathrm{He}$ licobacter pylori Triggers DNA Double-Strand Breaks and a DNA Damage Response in Its Host Cells," Proceedings of the National Academy of Sciences, Vol. 108, 2011, Article ID: 14944.

http://dx.doi.org/10.1073/pnas.1100959108

[9] E. Karczewska, I. Wojtas, E. Sito, et al., “Asessment of CoExistance of Helicobacter pylori and Candida Fungi in Diseases of the Upper Gastrointestinal Tract," Journal of Physiology and Pharmacology, No. S6, 2009, pp. 33-39.

[10] V. V. Chernin, V. M. Bondarenko, V. M. Chervinets and S. N. Bazlov, "Dysbacteriosis of Mucosal Microflora of the Gastroduodenal Zone in Inflammatory and Ulcer Lesions: Diagnosis and Classification,” Terapevticheskil arkhiv, Vol. 80, No. 2, 2008, pp. 21-25.

[11] J. G. Holt, "Bergey's Manual of Determinative Bacteriology,” Williams \& Wilkins, Baltimore, 1994.

[12] N. Z. Minaeva, U. M. Nesvizhsky, V. I. Minaev, L. V. Kudriavtseva, S. V. Zaitseva, K. I. Chekalina, B. L. Cherkasskii and P. L. Shcherbakov, "Mikrobiologicheskaia Diagnostika Zabolevanii, Vyzvannykh Mikroaerofil’Nymi Izognutymi Bakteriiami. M., 2001, 42 p. 